\title{
Non-cancer diseases requiring admission to hospital among German seafarers
}

\author{
Marcus Oldenburg $^{1}$, Volker Harth ${ }^{1}$, Ulf Manuwald ${ }^{2}$ \\ ${ }^{1}$ Institute for Occupational and Maritime Medicine, ZfAM, University Medical Centre Hamburg-Eppendorf, Germany \\ ${ }^{2}$ Health Sciences/Public Health, Carl Gustav Carus Technische Universität Dresden, Germany
}

\begin{abstract}
Background: This study estimated the discharge diagnosis due to non-cancer diseases of German seamen employed on German vessels in comparison to the general German male population.

Materials and methods: In a database, the German health insurance company for seafarers determined the discharge diagnoses from hospital for all German seafarers. In the time period from January 1997 to December 2007, this database encompassed on average more than 21,000 German seamen per year. It served as a source for comparison with the official national database on discharge diagnoses from the general German population. Thus, the standardised hospitalisation ratio (SHR) could be calculated.

Results: During the above mentioned time period, the most prominent non-cancer diagnoses among seafarers were diseases of the circulatory system, diseases of the digestive system, diseases of the musculoskeletal system, as well as injury and poisoning. Compared to the reference population, decreased SHRs were observed for almost all examined diseases with the exception of asbestosis (SHR: 1.79; $95 \% \mathrm{Cl} 0.65-3.90)$. In contrast to the deck and engine room crew, the galley staff demonstrated an increased SHR for almost all examined diseases, particularly for lifestyle-related diseases.

Conclusions: Although the presented data are likely biased by the healthy worker effect and by underreporting due to treatment on board or abroad, an elevated SHR for (lifestyle-related) diseases was observed in the galley staff. Therefore, especially this occupational group seems to need specific advice on healthy behaviours both on board and ashore.
\end{abstract}

(Int Marit Health 2015; 66, 1: 6-10)

Key words: hospitalisation, non-cancer, seafarers, lifestyle, health hazards

\section{INTRODUCTION}

It has been repeatedly described that the seafarer's job is associated with numerous occupational risks, fatigue, isolation, high physical demands and an elevated stress level on board [1, 2]. Particularly their risk for accidents at the workplace is increased compared to that of employees ashore [3]. The unique living and working situation of seafarers can also lead to emotional and physical exhaustion as well as to work-related diseases [4].

Diesel exhaust emissions from vessels contain toxic air contaminants (sulphur dioxide [SO2], nitrogen oxides [NOx]) and particulate components. When released into the atmosphere, these fine particles can cause acute shortterm symptoms such as headache, coughing, difficult or laboured breathing, tightness of chest, and irritation of the eyes and nose. Seafarers with long-term exposures to diesel exhaust are at risk for chronic, serious health problems such as cardiovascular disease, cardiopulmonary disease and lung cancer [5]. Besides diesel exhaust, the occupational exposure to toxic substances in shipboard working materials (paints, solvents) or in transported goods (benzene) can constitute a risk factor for acute or chronic diseases [6-8].

A recent German study on hospitalisation of German seafarers due to cancer revealed an elevated standardised

Marcus Oldenburg, MD, Institute for Occupational and Maritime Medicine, Seewartenstrasse 10, 20459 Hamburg, Germany, tel: +49 40428374308 ,

fax: +49 40427311393 , e-mail: marcus.oldenburg@bgv.hamburg.de 
hospitalisation ratio (SHR) for malignant neoplasms at all sites, for leukaemia, non-Hodgkin lymphoma, for respiratory cancer, and for non-melanoma skin cancer [9]. In contrast, this study estimates the SHR due to non-cancer diseases in German seafarers employed on German vessels. The knowledge about the prevalence of diseases among seafarers is a crucial precondition for specific prevention on board. Up to now, however, no study has been conducted on the frequencies of non-cancer diseases requiring admission to hospital among German seafarers.

\section{MATERIALS AND METHODS}

In Germany, all German seafarers working on German-flagged vessels were compulsorily insured with the health insurance company for seafarers up to January 2008. Therefore, the insurance company registered all hospitalisations of these seafarers in their database up to this date. In this study, this database served as information source for the seafarers' hospital admissions; the first discharge diagnoses were evaluated for all German seafarers treated in German hospitals from January 1997 to December 2007. Furthermore, this survey included only those German seamen who had been employed over cumulatively more than 365 seafaring days on board a German-flagged vessel in the above-mentioned time period. On average, more than 21,000 Germen seamen were included per year $(13,965$ deck crew, 5,930 engine room crew and 1,828 galley staff).

On the basis of our available pivot tables about seafarers' hospitalisation, it was possible to analyse the hospital admissions in consideration of the seamen's current occupational shipboard group (deck crew, engine room crew and galley personnel) and vessel at the end of each year within the examination period. Thus, the seamen were annually assigned to their past shipboard jobs and vessel types per year

The competent ethic commission approved this study.

The first discharge diagnosis of each patient who had been admitted to German hospitals is also recorded in the national hospital statistics for the population of the Federal Republic of Germany. These statistics are carried out jointly by the statistical offices of the German Government and the Federal States as an annual total compulsory survey (https:// www.gbe-bund.de/). All German hospitals in Germany are included in this survey. The hospitals provide patient-related characteristics and the main diagnosis of hospitalisation.

In consideration of the different age distribution in each year of the examination period, the seamen's hospitalisations due to non-cancer diagnoses were compared with those of the general German male population in the same time period. Thus, the seafarers' risk for non-cancer diseases could be expressed as indirect age and calendar time SHR $[9,10]$. In detail, as numerator the observed number was the total number of the first hospitalisations from each diagnosis in the cohort of seamen during the period under observation. The expected number - as denominator - was the number of seamen in each age group (age groups 15-24, 25-34, 35-44, 45-54, 55-64, 65-74 years and older than 75 years) for each examination year multiplied with the respective age-, and calendar period-specific hospitalisations rate in the national cohort. The SHR was calculated by division of the observed number with the expected number based on standard procedures of standardised mortality ratio (SMR) or standardised incidence ratio (SIR) [11].

Confidence intervals $(95 \% \mathrm{Cl})$ were calculated according to the Byar method. All calculations were performed with IBM SPSS Statistics 20.0 (2012) and Microsoft Excel (2010).

\section{RESULTS}

Out of the available ICD-9 main categories for non-cancer diagnoses, diseases of the circulatory system $(n=13,581)$, diseases of the digestive system $(n=6,924)$, diseases of the musculoskeletal system and connective tissue ( $n=5,077)$, injury and poisoning ( $n=4,818)$ as well as diseases of the respiratory system ( $n=3,217)$, in decreasing order, were most frequently found among seafarers (Table 1). Referring to the selected sub-categories, ischaemic heart diseases $(n=4,852)$ as well as diabetes mellitus $(n=958)$ dominated in the examined seafaring population.

Compared to the reference population, decreased SHRs - mostly on a significant level - were observed for diseases of the circulatory (hypertensive/ischaemic heart diseases, chronic pulmonary heart disease), digestive (ulcers as well as endocrine/nutritional disorders, diabetes mellitus), musculoskeletal, genitourinary and respiratory (emphysema, asthma) systems as well as for infectious or parasitic diseases. According to the present data, the risk for injury and poisoning was also not elevated among German seafarers (Table 1).

After distinguishing between the different types of vessels, the crews on fishing vessels had a significantly increased SHR for injury and poisoning compared to the other seamen (SHR 1.23; 95\% Cl 1.13-1.33 vs. SHR 0.89; 95\% Cl 0.87-0.92; data not shown). Additionally, a slightly increased SHR for diseases of the musculoskeletal system was found among fishermen, compared to a decreased SHR among the other seamen (SHR 1.08; 95\% Cl 0.99-1.19 vs. SHR 0.89; 95\% Cl 0.87-0.92; data not shown).

In respect of the different occupational shipboard groups, the galley staff demonstrated - in contrast to the other both occupational groups - an increased SHR for almost all examined diseases, especially for lifestyle-related diseases (endocrine, nutritional and metabolic diseases, respiratory [asthma] and digestive diseases [e.g. diabetes mellitus, gastric ulcer]) (Table 2). The galley staff also had a significantly elevated SHR for injuries and poisoning as well as for infectious and parasitic diseases. 
Table 1. Standardised hospitalisation ratios (SHR) for selected non-cancer diagnoses among male German seafarers in the period 1997-2007

\begin{tabular}{|c|c|c|c|c|}
\hline Diagnosis (ICD-9 code) & Observed number & Expected number & SHR & $(95 \% \mathrm{Cl})$ \\
\hline Diseases of the circulatory system (390-459) & 13,581 & $15,177.0$ & 0.89 & $(0.88-0.91)$ \\
\hline Hypertensive disease (401-405) & 602 & 792.1 & 0.76 & $(0.70-0.82)$ \\
\hline Ischaemic heart disease (410-414) & 4,852 & $6,093.2$ & 0.80 & $(0.77-0.82)$ \\
\hline Chronic pulmonary heart disease (416) & 29 & 35.4 & 0.82 & $(0.55-1.18)$ \\
\hline Diseases of the digestive system (520-579) & 6,924 & $7,220.9$ & 0.96 & $(0.94-0.98)$ \\
\hline Gastric, duodenal and peptic ulcers (531-533) & 389 & 389.0 & 1.00 & $(0.90-1.10)$ \\
\hline $\begin{array}{l}\text { Diseases of the musculoskeletal system } \\
\text { and connective tissue (710-739) }\end{array}$ & 5,077 & $5,604.5$ & 0.91 & $(0.88-0.93)$ \\
\hline Injury and poisoning (800-999) & 4,818 & $5,220.0$ & 0.92 & $(0.90-0.95)$ \\
\hline Diseases of the genitourinary system $(580-629)$ & 3,316 & $3,487.7$ & 0.95 & $(0.92-0.98)$ \\
\hline Diseases of the respiratory system $(460-519)$ & 3,217 & $3,514.1$ & 0.92 & $(0.88-0.95)$ \\
\hline Emphysema (492) & 16 & 27.8 & 0.58 & $(0.33-0.94)$ \\
\hline Asthma (493) & 74 & 89.9 & 0.82 & $(0.65-1.03)$ \\
\hline Asbestosis (501) & 6 & 3.4 & 1.79 & $(0.65-3.90)$ \\
\hline $\begin{array}{l}\text { Endocrine, nutritional and metabolic diseases, } \\
\text { and immunity disorders (240-279) }\end{array}$ & 1,487 & $1,702.5$ & 0.87 & $(0.83-0.92)$ \\
\hline Diabetes mellitus (250) & 958 & 1011.7 & 0.95 & $(0.89-1.01)$ \\
\hline Infectious and parasitic diseases (1-139) & 877 & 991.2 & 0.88 & $(0.83-0.95)$ \\
\hline
\end{tabular}

\section{DISCUSSION}

At sea, seafarers experience high physical demands such as rough seas, storm, cold and operating heavy equipment on a slippery deck. Thus, seafaring requires great effort from the body and muscles [12]. Furthermore, ship crews are exposed to a high level of psycho-social stress that may also enhance their known increased risk for occupational accidents and injuries $[13,14]$. Therefore, an elevated SHR for injury and poisoning was expected among seafarers compared to the reference population. In this study, however, this risk was slightly decreased in the total group. When distinguishing between the types of vessels, the crews on fishing vessels showed a slightly increased SHR for injuries that is likely explained by their handling heavy fishing gear on deck and by the fish processing activities at sea over several hours per day [10].

In addition, it was assumed that ship movements during voyages - especially on smaller vessels like fishing boats - can cause musculoskeletal diseases. In line with the findings from Hansen et al. [3], however, this study demonstrated a decreased SHR for diseases of the musculoskeletal system among seamen (with the exception of fishermen).

The present study revealed that diseases of the circulatory and digestive systems were the most prominent health disorders leading to hospitalisation among seafarers. Compared to the German reference population, seamen showed a significantly decreased risk for these diseases (with the exception of the galley personnel). Particularly the low risk for diseases of the circulatory system among seafarers was surprising; typical shipboard malnutrition combined with an increased proportion of smokers, the lack of exercise and high job-related stress on board are crucial contributory risk factors for cardiovascular diseases in seafaring $[15,16]$. Shift work and especially irregular working hours (which are typical in seafaring) may also lead to an increased hospitalisation risk for cardiovascular diseases in seafarers [17]. Among Danish seafarers, even elevated cardiovascular mortality was found that was supposed to be mainly caused by their shipboard lifestyle [18]. The hospitalisation study by Hansen et al. [3], however, also confirmed a lower SHR for acute myocardial infarction among seafarers in accordance with the present study results. These findings can be mainly interpreted as a healthy-worker effect due to the biennial medical fitness examinations in seafaring.

In the light of the known high tobacco consumption among seafarers [19-22], an elevated SHR for respiratory diseases was expected. Furthermore, seafarers are exposed at their working place to a variety of materials with harmful effects on their airways - ranging from organic solvents and mineral oils to exhaust gases, asbestos and a variety of hazardous cargoes [19]. Consequently, an increased incidence of respiratory diseases among seafarers was assumed. In this study, however, apart from the galley staff 
Table 2. Standardised hospitalization ratios (SHR) for selected non-cancer diagnoses among male German seafarers in the period 1997-2007

\begin{tabular}{|c|c|c|c|}
\hline \multirow[t]{2}{*}{ Diagnosis (ICD-9 code) } & \multicolumn{3}{|c|}{ SHR (95\% CI) [0: observed; E: expected] } \\
\hline & Deck crew & Engine room crew* & Galley personnel \\
\hline Diseases of the circulatory system (390-459) & $\begin{array}{l}0.91(0.89-0.93) \\
0: 8,400 ; \mathrm{E}: 9,200.4\end{array}$ & $\begin{array}{l}0.82(0.79-0.84) \\
0: 3,657 ; E: 4,475.5\end{array}$ & $\begin{array}{l}1.13(1.07-1.20) \\
0: 1,232 ; E: 1,087.5\end{array}$ \\
\hline Hypertensive disease (401-405) & $\begin{array}{l}0.74(0.66-0.82) \\
0: 352 ; E: 477.7\end{array}$ & $\begin{array}{l}0.76(0.65-0.88) \\
0: 176 ; E: 233.1\end{array}$ & $\begin{array}{l}1.02(0.78-1.32) \\
0: 59 ; E: 57.6\end{array}$ \\
\hline Ischaemic heart disease (410-414) & $\begin{array}{l}0.84(0.81-0.87) \\
0: 3,086 ; \mathrm{E}: 3,682.5\end{array}$ & $\begin{array}{l}0.71(0.67-0.75) \\
0: 1,282 ; \mathrm{E}: 1,804.3\end{array}$ & $\begin{array}{l}0.90(0.81-0.99) \\
0: 394 ; E: 437.8\end{array}$ \\
\hline Diseases of the digestive system (520-579) & $\begin{array}{l}0.98(0.95-1.01) \\
0: 4,246 ; \mathrm{E}: 4,338.4\end{array}$ & $\begin{array}{l}0.83(0.79-0.87) \\
0: 1,736 ; \mathrm{E}: 2,082.5\end{array}$ & $\begin{array}{l}1.31(1.22-1.41) \\
0: 707 ; E: 539.0\end{array}$ \\
\hline Gastric, duodenal and peptic ulcers (531-533) & $\begin{array}{l}1.01(0.89-1.15) \\
0: 238 ; E: 235.4\end{array}$ & $\begin{array}{l}0.85(0.69-1.04) \\
0: 96 ; E: 113.0\end{array}$ & $\begin{array}{l}1.55(1.12-2.08) \\
0: 44 ; E: 28.4\end{array}$ \\
\hline $\begin{array}{l}\text { Diseases of the musculoskeletal system } \\
\text { and connective tissue (710-739) }\end{array}$ & $\begin{array}{l}0.90(0.86-0.93) \\
0: 2,998 ; \mathrm{E}: 3,347.4\end{array}$ & $\begin{array}{l}0.88(0.83-0.93) \\
0: 1,423 ; E: 1,620.0\end{array}$ & $\begin{array}{l}1.11(1.02-1.22) \\
0: 473 ; E: 424.8\end{array}$ \\
\hline Injury and poisoning (800-999) & $\begin{array}{l}0.90(0.87-0.94) \\
0: 2,812 ; \mathrm{E}: 3,120.1\end{array}$ & $\begin{array}{l}0.89(0.84-0.94) \\
0: 1,286 ; E: 1,447.5\end{array}$ & $\begin{array}{l}1.21(1.11-1.33) \\
0: 488 ; E: 402.1\end{array}$ \\
\hline Diseases of the genitourinary system $(580-629)$ & $\begin{array}{l}0.94(0.90-0.98) \\
0: 1,988 ; \mathrm{E}: 2,109.3\end{array}$ & $\begin{array}{l}0.91(0.85-0.97) \\
0: 922 ; \mathrm{E}: 1,011.1\end{array}$ & $\begin{array}{l}1.25(1.11-1.39) \\
0: 318 ; E: 255.1\end{array}$ \\
\hline Diseases of the respiratory system $(460-519)$ & $\begin{array}{l}0.92(0.88-0.96) \\
0: 1,964 ; \mathrm{E}: 2,130.2\end{array}$ & $\begin{array}{l}0.84(0.78-0.90) \\
0: 843 ; E: 1,004.7\end{array}$ & $\begin{array}{l}1.21(1.08-1.35) \\
0: 312 ; E: 257.3\end{array}$ \\
\hline Asthma (493) & $\begin{array}{l}0.85(0.62-1.13) \\
0: 46 ; E: 54.1\end{array}$ & $\begin{array}{l}0.51(0.27-0.87) \\
0: 13 ; \mathrm{E}: 25.5\end{array}$ & $\begin{array}{l}1.94(1.03-3.31) \\
0: 13 ; E: 6.5\end{array}$ \\
\hline $\begin{array}{l}\text { Endocrine, nutritional and metabolic diseases, } \\
\text { and immunity disorders (240-279) }\end{array}$ & $\begin{array}{l}0.76(0.71-0.82) \\
\text { O: } 783 ; \mathrm{E}: 1,025.5\end{array}$ & $\begin{array}{l}0.84(0.77-0.93) \\
0: 420 ; E: 497.6\end{array}$ & $\begin{array}{l}1.75(1.53-2.00) \\
0: 219 ; E: 124.8\end{array}$ \\
\hline Diabetes mellitus (250) & $\begin{array}{l}0.78(0.71-0.85) \\
0: 475 ; E: 609.9\end{array}$ & $\begin{array}{l}0.93(0.82-1.04) \\
0: 275 ; E: 296.6\end{array}$ & $\begin{array}{l}2.18(1.86-2.54) \\
0: 161 ; E: 73.8\end{array}$ \\
\hline Infectious and parasitic diseases (1-139) & $\begin{array}{l}0.81(0.74-0.88) \\
0: 483 ; E: 597.6\end{array}$ & $\begin{array}{l}0.82(0.72-0.94) \\
0: 231 ; E: 280.6\end{array}$ & $\begin{array}{l}1.77(1.48-2.10) \\
0: 131 ; E: 74.0\end{array}$ \\
\hline
\end{tabular}

*Without ship mechanics (with normally changing workplaces). Significant results are bold. $\mathrm{Cl}$ - confidence interval

an elevated SHR for asthma was not observed. It is unclear whether the observed lower SHR for asthma among deck and engine room crew might be caused by the fresh climate at sea, which is low in allergens.

Furthermore, the SHR for asbestosis was increased in this study. Asbestos had been introduced into ship construction in the late $19^{\text {th }}$ century and was used as insulation material until the mid-1990s. During the lifetime of a ship, heat and aging of the asbestos insulation products lead to increased friability whereby natural movements and vibrations of the ship's structure enhanced fibre release. It is assumed that particularly engine personnel have repeated exposure to asbestos during running repairs [23]. In this study, although only a few patients with asbestosis had been determined (mostly among technical officers on tankers or cargo ships), these hospitalisations can be regarded as an occupational-related disease [19].

Moreover, owing to the ships' stays in ports with lower hygienic standards, a higher SHR for infectious or parasitic diseases was expected among seafarers. In the present study, however, this was only observed among the galley staff. According to the entries documented in 49 medical log books from seagoing cargo ships under German flag, nearly one fourth of the visits to the ship's infirmary were due to presumably communicable diseases, indicating the high relevance of infectious diseases in seafaring [24]. In cases of health problems aboard, seafarers can use the ship's infirmary and be treated by the ship's officer in charge of medical care. Thus, some - particularly acute - diseases may only be treated at sea and are consequently not counted in hospitalisation statistics. Therefore, it cannot be excluded that treatment at sea had diminished the hospitalisation ratios among seafarers. In addition, some seamen might conceal their shipboard health problems requiring hospitalisation to avoid an expected subsequent relief on board.

In accordance with a survey of Hansen et al. [3], the galley staff in this study showed an increased SHR particularly for lifestyle-related diseases such as nutritional (e.g. diabetes), airway and gastrointestinal diseases as well as injuries. Lifestyle-related diseases are assumed to be caused by malnutrition, tobacco smoking, alcohol consumption, high 
stress, lack of exercises and risky behaviour. Several of these risk factors are observed among galley and catering crew as high-calorie food is always available in mess rooms and eating is one of the most favoured activities in leisure time on board. Previous studies observed that the galley staff is often less qualified than deck and engine room personnel, indicating a lower socioeconomic status with a consequently higher risk for lifestyle-related diseases [25, 26].

\section{LIMITATIONS OF THE STUDY}

As a limitation of this study, the biennial medical fitness tests for seafarers constitute a healthy worker effect. Furthermore, some health disorders at sea can be appropriately managed on board or treated without urgent hospitalisation and were not registered in the seafarer database. Both aspects could have led to an underestimation of disease frequencies among seafarers; furthermore, the treatments in hospitals abroad were not registered in this study. However, it is likely that many seafarers with severe health diseases were referred to a German hospital in the course of time [15].

Acute health disorders in seafarers can be caused both by their job-related exposure (e.g. kind and frequency of contact with hazardous substances, stress level on board) and by lifestyle-related behaviour (smoking, alcohol). Unfortunately, data on these hazards are not available in this study. Thus, it is impossible to determine to what extent the seafarers' decreased SHR for most of the examined non-cancer diseases was attributed to their job-related hazards. In the light of the observed elevated SHR for lifestyle-related diseases among the galley staff, this occupational group seems to need specific advice on healthy behaviours.

\section{CONCLUSIONS}

In total, further studies are needed to elucidate the risk of seafarers for non-cancer diagnosis, taking into consideration the job-related exposure as well as their lifestyle-related behaviour.

\section{ACKNOWLEDGEMENTS}

The authors thank Mr Graf, Ms Lehmann and Ms Mirza from the Verkehrs-Berufsgenossenschaft for providing the seafarers' discharge data.

\section{AUTHORSHIP}

M. Oldenburg, U. Manuwald and V. Harth were involved in conception, discussion and design of this manuscript. U. Manuwald made the statistical analysis. M. Oldenburg interpreted the data and wrote the paper.

\section{REFERENCES}

1. Oldenburg M, Jensen $\mathrm{HJ}$. Merchant seafaring: a changing and hazardous occupation. Occup Environ Med 2012; 69: 685-688.
2. Roberts SE. Occupational mortality in British commercial fishing, 1976-95. Occup Environ Med 2004; 61: 16-23.

3. Hansen HL, Tuchsen F, Hannerz H. Hospitalisations among seafarers on merchant ships. Occup Environ Med 2005; 62: 145-150.

4. Oldenburg M, Jensen $\mathrm{HJ}$, Wegner R. Burnout syndrome in seafarers in the merchantmarine service. IntArch Occup Environ Health 2013;86:407-416.

5. Raaschou-Nielsen O, Andersen ZJ, Beelen R et al. Air pollution and lung cancer incidence in 17 European cohorts: prospective analyses from the European Study of Cohorts for Air Pollution Effects (ESCAPE). Lancet Oncol 2013; 14: 813-822.

6. Dryver E, Brandt L, Kauppinen T, Olsson H. Occupational exposures and non-Hodgkin's lymphoma in Southern Sweden. Int J Occup Environ Health 2004; 10: 13-21.

7. Fritschi L, Benke G, Hughes AM et al. Risk of non-Hodgkin lymphoma associated with occupational exposure to solvents, metals, organic dusts and PCBs (Australia). Cancer Causes Control 2005; 16: 599-607.

8. Vineis $\mathrm{P}$, Miligi L, Costantini AS. Exposure to solvents and risk of non-Hodgkin lymphoma: clues on putative mechanisms. Cancer Epidemiol Biomarkers Prev 2007; 16: 381-384.

9. Oldenburg M, Harth V, Manuwald U. Hospitalization due to cancer among German seafarers. AJIM accepted. 2015.

10. Oldenburg M, Harth V, Manuwald U. Comparison of hospitalization among German coastal and deep sea fishermen. IAOEH accepted. 2015.

11. Breslow NE, Day NE. Statistical methods in cancer research. Volume II:The design and analysis of cohort studies. IARC Sci Publ 1987; 82: 1-406.

12. Lawrie T, Matheson C, Murphy E, Ritchie L, Bond C. Medical emergencies at sea and injuries among Scottish fishermen. Occup Med (Lond) 2003; 53: 159-164.

13. Oldenburg $M$, Baur $X$, Schlaich C. Occupational risks and challenges of seafaring. J Occup Health 2010; 52: 249-256.

14. Jezewska M, Leszczynska I, Jaremin B. Work-related stress at sea self estimation by maritime students and officers. Int Marit Health 2006; 57: 66-75.

15. Kaerlev L, Dahl S, Nielsen PS et al. Hospital contacts for chronic diseases among Danish seafarers and fishermen: a population-based cohort study. Scand J Public Health 2007; 35: 481-489.

16. Oldenburg M. Risk of cardiovascular diseases in seafarers. Int Marit Health 2014; 65: 1-5.

17. Tuchsen F. Working hours and ischaemic heart disease in Danish men: a 4-year cohortstudy of hospitalization. Int J Epidemiol 1993; 22: 215-221.

18. Hansen HL, Pedersen G. Influence of occupational accidents and deaths related to lifestyle on mortality among merchant seafarers. Int J Epidemiol 1996; 25: 1237-1243.

19. Rafnsson V, Gunnarsdottir H. Cancer incidence among seamen in Iceland. Am J Ind Med 1995; 27: 187-193.

20. Casson FF, Zucchero A, Boscolo Bariga A et al. Work and chronic health effects among fishermen in Chioggia, Italy. G Ital Med Lav Ergon 1998; 20: 68-74.

21. Hansen HL, Jensen J. Female seafarers adopt the high risk lifestyle of male seafarers. Occup Environ Med 1998; 55: 49-51.

22. Scovill SM, Roberts TK, McCarty DJ. Health characteristics of inland waterway merchant marine captains and pilots. Occup Med (Lond) 2012; 62: 638-641.

23. Greenberg M. Cancer mortality in merchantseamen. Third wave if asbestos disease: exposure to asbestos in place. Annals of the New York Academy of Sciences, New York, 1991

24. Schlaich CC, Oldenburg M, Lamshoft MM. Estimating the risk of communicable diseases aboard cargo ships. J Travel Med 2009; 16: 402-406.

25. Nilsson R. Cancer in seamen with special reference to chemical health hazards. Department of Internal Medicine, Section of Occupational Medicine, Göteborg University, 1998.

26. Oldenburg M, Harth V, Jensen HJ. Overview and prospect: food and nutrition of seafarers on merchant ships. Int Marit Health 2013; 64: 191-194. 